\title{
Introducción del darwinismo al contexto colombiano
}

\author{
Introduction of the Darwinism to the Colombian context
}

John Richard Jiménez Peñuela

Asesor Pedagógico Eyeth Films $®$ www.eyethfilms.webs.com

\section{Resumen}

Esta presentación plantea puntos básicos sobre la introducción del paradigma evolutivodarwiniano al contexto colombiano, tomando como precedente el desarrollo de la "Expedición Botánica" y la "Comisión Corográfica", analizando los sucesos en tomo a la aparición de los primeros programas de Biología en las universidades del país, desde un enfoque holístico que comprenda los aspectos sociales, políticos, culturales y de formación académica y cient́fica en Colombia y los ambientes académicos en los cuales se dio la controversia.

\section{Palabras clave}

Darwinismo en Colombia, Comisión Corográfica, Universidad Nacional, autoridad religiosa, autoridad científica

\section{Abstract}

This presentation raises points about the introduction of the evolutionary-Daruinian paradigm, to the Colombian context, taking as precedent the development of the "Comisión Corográfica" and the "Expedición Botánica", analyzing the events surrounding the emergence of the first Biology programs at the country's universities from a holistic approach encompassing the social, political, cultural and academic and scientific training in Colombia and academic environments in which the dispute occurred.

\section{Keywords}

Darwinism in Colombia, Comisión Corográfica, Universidad Nacional, religious authority, scientific authority

\section{Preámbulo}

A doscientos años del nacimiento de Charles Darwin, estudiar el desarrollo de su teoría en Colombia es ineludible para la comprensión holística de la historia de la enseñanza de las ciencias, al abordar entre otros aspectos los modelos políticos y de gobiemo de cada época y los variados matices de aceptación o rechazo que tienen los nuevos paradigmas entre los diversos públicos de la sociedad, tales como la separación total representada por el Creacionismo absoluto, la acomodación a otras ciencias no naturales en el caso del Darwinismo social, y la fusión con aspectos religiosos como ocurre en la Evolución Teísta.
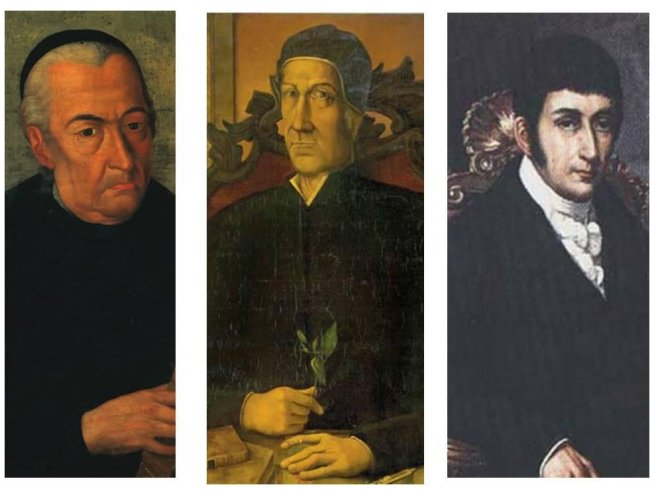

Figura 1. Personajes principales de la Expedición Botánica: José Celestino Mutis, Eloy Valenzuela, Francisco José de Caldas. 


\section{Antecedentes}

En el avance preliminar que tuvieron las ciencias naturales desde la historia natural hasta la biología actual, los trabajos que presentan mayor relevancia cient́fica e influencia en este proceso fueron los de la Expedición Botánica y la Comisión Corográfica (Quevedo, 1993).

Durante el gobierno de Tomas Cipriano de Mosquera (1845-1849), se dieron reformas que estimulaban el comercio exterior a través de la introducción del sistema métrico, mejoras en las estadísticas y creación de vías que permitieran el transporte de los productos, entre otros.

Este nuevo ambiente posibilitó la organización Comisión Corográfica (1850-1859), que asumió la responsabilidad de "hacer una descripción del territorio nacional que revelara las condiciones físicas, morales y políticas de la nación", marcando un precedente en investigación a pesar de contar con apoyo económico y político débil. La Comisión señaló perspectivas de desarrollo regional, contribuyendo a la construcción de la identidad nacional (Becenra y Restrepo, 1993)'

Como antecedente inmediato de esta empresa, la Real Expedición Botánica del Nuevo Reino de Granada (1783-1816), fue un proyecto que no solo posibilitó el reconocimiento de la flora y fauna local, sino también la futura explotación de los recursos
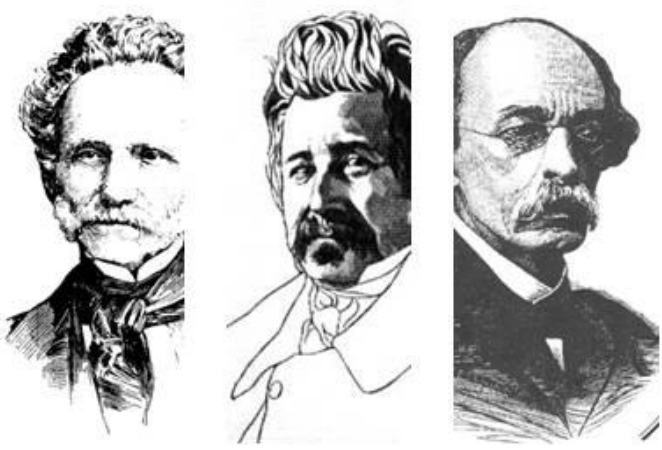

Figura 2. Personajes principales de la Comisión Corográfica: Tomas Cipriano de Mosquera, Agustín Codazzi y Manuel Ancizar. como los minerales y medicinales por parte de la Corona Española y la divulgación del pensamiento científico ilustrado europeo. Abarcó cerca de 8000 kilómetros de climas y regiones diversos, catalogando más de 20.000 plantas y 7.000 animales, muchos de los cuales fueron ilustrados con altísimo detalle.

Fue dirigida por la figura central de las ciencias de la Nueva Granada, José Celestino Mutis, médico del Real Colegio de Cirugía de su Cádiz natal, mas adelante ordenado sacerdote. Mantuvo contacto epistolar con el máximo investigador de las ciencias naturales de la época, el sueco Carlos Linneo, hasta que este murió. Esto, porque los medios de transporte por mar o tierra eran tan escasos, lentos, arriesgados y costosos como para permitir un contacto personal.

El pensamiento de Linneo en cabeza de Mutis, permeó el ambiente académico colombiano de la época con su premisa de vislumbrar la sabiduría de Dios, su orden universal a través del estudio de Su Creación. Y a diferencia de la propuesta darwiniana que asume el tiempo y la selección natural como factores fundamentales en la transformación de los seres vivos y su descendencia, consideraba la creación de un universo inmutable. Es así que, Mutis utilizó el sistema linneano de nomendatura binominal para clasificar y nombrar con precisión las especies animales y vegetales coleccionadas durante su gran travesía.

Por lo anterior, se considera que la introducción de los estudios de Filosofía o Historia Natural en la Nueva Granada se debió en gran parte por la labor intelectual desplegada por Mutis como difusor del pensamiento ilustrado en Hispanoamérica, a través de la descripción de los fenómenos de la naturaleza, sus causas, relaciones, constitución, dasificación y orden que evidencian el plan del Creador. Este sería el panorama de las ciencias naturales casi que inmodificable hasta la llegada del darwinismo. 


\section{Introducción del darwinismo al contexto colombiano}

Aunque Darwin era una autoridad científica bastante reconocida en Inglaterra, su pensamiento tendría que abrirse camino en otras latitudes para ser reconocido de acuerdo a los escenarios sociales presentes. De esta manera, es probable que su teoría ingresara a un contexto colombiano más amplio que el demarcado por el ámbito puramente científico, ya que era discutido en ćrculos principalmente filosóficos y políticos, en parte porque la Sociedad de Naturalistas creada en 1859 apenas comenzaba a consolidarse y plantearse como institución investigadora. Además, campos del conocimiento con mayor desarrollo que la biología contaban con sus propios baluartes científicos como por ejemplo Pasteur en el caso de la medicina.

Sin embargo, las fundaciones de la Universidad Nacional de los Estados Unidos de Colombia mediante Ley 16 de 1867 y reglamentada el 13 de enero de 1868 y de la Universidad de Antioquia el 14 de diciembre de 1871, son fundamentales en la historia del darwinismo colombiano, a partir de su inserción en los programas de ciencias naturales porque es allí donde se manifestó abiertamente, con buena acogida por el liberalismo de entonces muy propenso a un daruinismo de corte social, en oposición a la autoridad eclesiástica representada por el conservatismo.

Es de recalcar nuevamente que este pensamiento en un primer momento no hizo parte de la investigación en los programas académicos. En cambio, fue debatido fervientemente al interior de los cursos de historia, geografía, filosofía moral, biología, psicología y sociología, tanto así que en la década de 1890, las escuelas y universidades dirigidas por dérigos lo discutían, aunque sin disociarlo de la sociología, la filosofía y las ciencias naturales, enfrentando. Como ilustración de dichas confrontaciones se encuentran los escritos de Emilio Cuervo Márquez y Santiago Calvo (Restrepo y Becerra, 1995).

En 1891, el Colegio Mayor Nuestra Señora del Rosario abre un conaurso para los estudiantes de la dase de Filosofía y Metafísica que consistía en escribir "una tesis sobre el sistema evolucionista, comparándolo con la doctrina monogénica de la Sagrada Escritura", esta última apoyada por la herencia del pensamiento Linnenano de Mutis. Emilio Cuervo Márquez, un joven de 18 años ganó con su ensayo titulado "Estudio sobre el sistema evolucionista". Ajeno a este concurso era su excompañero del curso de religión de la misma universidad, Santiago Calvo, de 20 años, quien escribió el libro: "El evolucionismo en su aspecto físico, psicológico, moral y político" (Restrepo y Becenra, 1995).

Ambos autores examinaron a profundidad el darwinismo centrado en la evolución por selección natural, aunque haciendo abordajes a problemas que trascienden el campo de las ciencias naturales y las teorías biológicas. De esta manera, develan la falta de acuerdos sobre lo que significaba el evolucionismo, siendo más evidente en el de Calvo al usar términos como "sistema" el cual tiene "muchas posibles direcciones", dirigiendo "la atención hacia la "filosofía" y "metafísica". Los dos apoyan sus discursos en autores con autoridad científica, cumpliendo roles mas similares al un divulgador, que al de un investigador (Restrepo y Becerra, 1995).

Otro aspecto que es considerable es la posición defensiva de Cuervo, al igual que la mayoría de autores en el siglo XIX cenrada a la discusión sobre la veracidad de las teorías científicas, pues la ciencia se constituía en un desafío a la autoridad de la iglesia, en este caso de la teoría monogénica de la Sagrada Escritura, que como lo exigía el concurso no debía ser refutada. En cambio, Calvo es más decidido a usar argumentos científicos para defender la posición de veracidad del darwinismo argumentando la incompatibilidad entre la metafísica y las ciencias, al permitir estas .últimas explicaciones de tipo analítico y postulación de leyes como la de la gravedad (Restrepo y Becenra, 1995)

Ante dicha polarización de ambos escritores, se encuentra que: 
"movilizada a favor o en contra de la posición que se quiere sostener, en una compleja trama argumental, aquella comunidad (de los sabios) decide la cuestión que se discute, frente a la cual los "difusores" no tienen nada que añadir, nada que objetar (Restrepo y Becerra, 1995):

Tal sería el panorama de las ciencias ejemplificado en las obras de los dos autores donde el nuevo elemento del darwinismo devela dos autoridades; una religiosa y otra cientúfica que influyeron a la elite intelectual, contribuyeron ideológicamente a los enfrentamientos que se venían dando entre radicalistas y autoridades edesiales. En este sentido, incidió en la política y la educación del país, al aportar directamente en la polarización de las corrientes filosóficas de los partidos dominantes, apoyando o refutando sus ideologías.

\section{Conclusiones}

Continuar investigaciones que partan de la historia de las ciencias y el ámbito social del darwinismo, permite conocer el tipo de cambios o adaptaciones que el pensamiento evolutivo ha tenido en el país, desde su bipolaridades precedentes (creación-evolución, liberales-conservadores, etc), hasta su indusión actual en los curnículos de ciencias de los diferentes niveles educativos.

De esta manera, al reconocer la influencia del darwinismo en los ámbitos académico y educativo colombianos, se posibilitará el hallazgo de las controversias como ocurrió en su llegada al contexto colombiano. Pero también, permitirá integrar o modificar otros modelos sobre los ońgenes, teorías y formas de corrientes religioso-filosóficas, contribuyendo a formular propuestas que contribuyan a una mejora educación en ciencias, para lo cual es necesario ahondar en la investigación de la historia de las ciencias hasta la actualidad.

De ahí la importancia de indagar las formas presentes del darwinismo para permitir una enseñanza de las ciencias ligada a los contextos altural y social, sin descuidar los referentes de otras latitudes como los países Suramericanos con contextos similares al colombiano, de los lugares de origen como Inglaterra, y de aquellos donde ha generado fuertes controversias como es el caso de Estados Unidos y Australia.

\section{Bibliografía}

Becerra Y Restrepo (1993). Las Ciencias en Colombia 1783-1993, Una perspectiva históricosociológica. En: Revista Colombiana de Educación. No. 26, p.39 - 43

Glick Thomas y Otros. (1999). El Daruinismo en España e Iberoamérica. Madrid: UNAM Editorial Doce Calles.

Quevedo Emilio y otros (1993). Historia Social de la Ciencia en Colombia, Tomo I Colombia: Colciencias.

Restrepo y Becenra (1995). 'Lectio, Disputatio, Dictatio' en el Nombre de la Ciencia: Una Polémica Evolucionista en Colombia. En: Historia Crítica. Bogotá. No. 10, p. 73 - 87. 